\title{
CUIDADO DE SI E FORMAÇÃO ÉTICO-ESTÉTICO-POLÍTICA: CONTRIBUIÇÕES FOUCAULTIANAS A UM PROCESSO DE PESQUISA
}

\author{
Roney Polato de Castro
}

\begin{abstract}
Resumo: O artigo tem como objetivo apresentar alguns dos modos como as teorizações foucaultianas afetaram um processo de pesquisa de doutorado em educação, com foco na formação docente, em uma disciplina do curso de Pedagogia que discute e problematiza as relações de gênero e sexualidades. A centralidade da argumentação apresenta as tentativas de aproximação com os últimos estudos de Michel Foucault sobre a ética e o cuidado de si. A noção foucaultiana de sujeito ético, que se constitui em práticas de si, de ação moral sobre si mesmo, foi uma ferramenta inquietante para pensar a formação docente com as atividades da disciplina, funcionando como um campo de constituição de sujeitos, ao instaurar relações das estudantes consigo mesmas, produzindo múltiplas subjetividades.
\end{abstract}

Palavras-chave: formação docente; cuidado de si; ética; Foucault; Pedagogia.

\section{CARE OF SELF AND ETHICAL-AESTHETIC-POLITICAL FORMATION: FOUCAULTIAN CONTRIBUTIONS TO A RESEARCH PROCESS}

\begin{abstract}
The article aims to present some of the ways in which Foucaultian theorizations have affected a doctoral research process in education, with a focus on teacher education in a discipline of the Pedagogy course that discusses and problematizes gender and sexuality relations. The centrality of the argument shows the attempts to approach Michel Foucault's latest studies on ethics and care of self. The Foucaultian notion of an ethical subject, which is constituted in self-practices, of moral action on oneself, was an unsettling tool to think about teacher education with the activities of the discipline, functioning as a field for the constitution of subjects, when establishing relationships between students with themselves, producing multiple subjectivities.
\end{abstract}

Keywords: teacher education; care of self; ethics; Foucault; Pedagogy.

\section{Introdução: inquietações na experiência com uma pesquisa}

Este artigo é fruto das discussões construídas por ocasião da realização de uma pesquisa de doutorado em Educação (CASTRO, 2014), com foco nas experiências vividas por estudantes do curso de Pedagogia de uma universidade pública. ao cursarem uma disciplina eletiva intitulada 'Gênero, Sexualidade e Educação' (GSE). Como deve ser possível perceber a partir do nome da referida disciplina, seu foco e escopo voltam-se para discussões que compõem os estudos de relações de gênero e sexualidades, cujos aportes podem ser utilizados para problematizar o campo da educação. Aqui, cabe ressaltar, a palavra 'educação' adquire contornos que extrapolam sentidos fixados historicamente, os quais a associam com a instituição escolar, seus sujeitos, processos e políticas. Sem abandonar tal perspectiva, ampliamos seus 
sentidos a partir das inspirações foucaultianas, pensando em educação como processos de produção de sujeitos e subjetividades. A pesquisa, portanto, tinha como centralidade esses processos, no atravessamento com uma disciplina que traz questões por vezes inquietantes e desafiadoras, constituindo subjetividades docentes em processos formativos ético-estético-políticos implicados na problematização de si e do mundo.

Neste artigo, busco apresentar alguns dos percursos dessa pesquisa que foram mais diretamente afetados pelas provocações foucaultianas, especialmente as tentativas de aproximação com os últimos estudos de Michel Foucault sobre a ética e o cuidado de si. 'Perturbação' e ‘inquietação' são palavras que dizem dos encontros com Foucault, dos quais se costuma sair atormentado/a, já que isso significa adentrar sua 'oficina', tomar de empréstimo suas ferramentas, produzir explosões em coquetéis Molotovii e fogos de artifício. Isso nos coloca um desafio: ser-lhe infiel e usar suas ferramentas no movimento de aproximações e distanciamentos, por vezes, inclusive, abandonando-as. Com a inspiração foucaultiana, a pesquisa foi se produzindo com questões moventes, que foram gerando outras questões para problematizar processos formativos, docências, relações de gênero, sexualidades, educação.

Constituiu-se uma pesquisa-experiência, em que não havia qualquer possibilidade de neutralidade na relação entre pesquisador e campo de pesquisa. Experiências de um docente foram se hibridizando às das estudantes ${ }^{\text {iii }}$ que cursavam a disciplina, produzindo um 'turbilhão' de aprendizados, sentimentos e saberes. A disciplina foi organizada como um convite às estudantes para pensarem a si mesmas, suas relações com outros e com o mundo e para construir narrativas de processos de subjetivação e dessubjetivação iv . Esse desafio foi lançado para que elas pudessem encontrar modos de não manter 'tudo como está', mas para poder pensar diferentemente, agir diferentemente, constituir uma ética e uma estética da existência (FOUCAULT, 2001; 2006a).

As inquietações em torno da questão de pesquisa se produziram com as atividades da disciplina, especialmente com as escritas narradas pelas estudantes em diários de bordo, artefatos constituídos na disciplina GSE para registrar os movimentos de pensamento, os sentimentos, as provocações instituídas com e a partir das aulas. Os diários de bordo foram tomados como fonte principal de construção dos dados da pesquisa, ou seja, foram problematizadas as narrativas escritas pelas estudantes a partir das relações construídas com a disciplina. Considerando a formação docente inicial, praticada nas universidades, como um complexo conjunto de mecanismos vinculados a contextos sociais, culturais e históricos específicos, são colocadas em ação certas estratégias por meio das quais as estudantes de Pedagogia em formação produzem ou transformam a experiência que têm de si mesmas, os modos como se tornam objetos para si mesmas e como suas experiências com os gêneros e as sexualidades são elaboradas e reelaboradas a partir das relações em que elas pensam a si mesmas (CASTRO, 2014). Tratando especificamente da disciplina que foi alvo da referida pesquisa, as aulas, os diários de bordo e demais atividades passam a funcionar como mecanismos desse processo, a partir do qual as estudantes produzem narrativas de si mesmas, enunciados 
de uma rede discursiva que envolve as aulas e vai muito além delas, englobando regimes discursivos mais amplos (discurso moral, religioso-cristão, jurídico, biológico, pedagógico). Esse processo se insere nos jogos de verdades que constituem as subjetividades das estudantes e a do docente, algo como

o resultado de um complexo processo histórico de fabricação no qual se entrecruzam os discursos que definem a verdade do sujeito, as práticas que regulam seu comportamento e as formas de subjetividade nas quais se constitui sua própria interioridade. É a própria experiência de si que se constitui historicamente como aquilo que pode e deve ser pensado. A experiência de si, historicamente constituída, é aquilo a respeito do qual o sujeito se oferece seu próprio ser quando se observa, se decifra, se interpreta, se descreve, se julga, se narra, se domina, quando faz determinadas coisas consigo mesmo, etc. (LARROSA, 2002, p. 43).

Desse modo, com Larrosa (2002), problematiza-se a ideia de que as práticas de formação têm papel produtivo, atuando como um investimento na produção de sujeitos-docentes que possam estar sensíveis às questões que envolvem as relações de gênero e as sexualidades no interior do espaço escolar e para além de seus 'muros'. Ao destacar esse processo, aponto as experiências com a disciplina como uma formação que investe na possibilidade de pensar diferentemente, olhar a partir de novos ângulos, exercitar o pensamento diante de situações cotidianas para as quais não há uma única resposta. Ao apostar na ideia de que a formação docente se constitui em mecanismo que funciona como "técnica de si" (FOUCAULT, 2006a), afastamo-nos de um absolutismo dessa formação, como se ela instituísse um processo definitivo e garantidor da fabricação de um sujeito completamente formado, capaz de resolver os problemas educacionais, de dar conta das mazelas sociais.

Nos caminhos trilhados na pesquisa, múltiplas experiências foram se constituindo e se atravessando na busca por aproximar o pesquisador de "uma atitude exigente, prudente, 'experimental", no sentido de poder "confrontar o que se pensa e o que se diz com o que se faz e o que se é" (FOUCAULT, 2006a, p. 219). Nesses caminhos, como nos sugere Foucault (2006a), se trata menos de 'aplicar' determinado referencial teórico a algumas práticas e mais de "experimentá-las e modificá-las", constituindo um modo de viver e de olhar o mundo, de enfrentar as tramas de saber-poder capilarizadas nos discursos e nas práticas cotidianas. Enfim, trata-se de entender que a teoria não expressará, traduzirá ou aplicará uma prática; a teoria é uma prática (FOUCAULT, 2006b), implicada nos conflitos e negociações que fazem parte dos processos de pesquisa, assumindo a dúvida e o questionamento como ferramentas fundamentais para se movimentar nesses processos. Falando de seu trabalho, Foucault (2006a) parece aproximar-se desse sentido que pode ser atribuído ao trabalho do/a pesquisador/a:

Quanto àqueles para quem se esforçar, começar e recomeçar, tentar, enganar-se, retomar tudo de fio a pavio, e ainda encontrar meios de hesitar a cada passo, àqueles para quem, em suma, trabalhar - ou seja, manter-se em reserva e na inquietação - 
equivale à demissão, é evidente que não somos do mesmo planeta (FOUCAULT, 2006a, p. 196).

Se a realização de pesquisas e a produção de conhecimentos estão constituídas pelos jogos de saberpoder-verdade, com efeitos de poder que são codificados e regulados (FOUCAULT, 2006c), a postura do pesquisador diante desse movimento de conhecer envolve, como apontam Kastrup, Tedesco e Passos (2008, p. 12), "uma posição em relação ao mundo e a si mesmo, uma atitude, um ethos". Trilhando os caminhos de uma pesquisa que problematizava os atravessamentos entre formação docente, relações de gênero e sexualidades, havia uma implicação pessoal e política, traduzida em modos particulares e subjetivos de pesquisar. Dessa forma, ao fazer pesquisa, define-se uma política de cognição, relacionada a uma "certa maneira de estar no mundo, de habitar um território existencial e de se colocar na relação de conhecimento" (idem). Tal política cognitiva está relacionada aos caminhos pela pesquisa que se constituíram a partir de experiências de atuação como docente e pesquisador que discute relações de gênero e sexualidades como construções sociais, culturais, históricas e discursivas. "Assumir essa postura requer uma virada, uma reversão da atitude naturalizada, o que exige, em princípio, um esforço. Mas pode se transformar numa prática, numa atitude encarnada, configurando uma nova política cognitiva” (KASTRUP, TEDESCO e PASSOS, 2008, p. 13).

Como tentei mostrar nesta introdução, o processo da pesquisa foi profundamente afetado pelas inquietações foucaultianas. O inquieto Foucault nos inquieta, nos tira do lugar e nos lança em problematizações que tornam a pesquisa uma atividade capaz de modificar nossas relações conosco mesmos e com o mundo. Como diz Deleuze (1992, p. 108): “Quando as pessoas seguem Foucault, quando têm paixão por ele, é porque têm algo a fazer com ele, em seu próprio trabalho, na sua existência autônoma. Não é apenas uma questão de compreensão ou de acordo intelectuais, mas de intensidade, de ressonância, de acorde musical". Para além das afetações no processo da pesquisa, busco apresentar o modo como me apropriei de algumas das teorizações foucaultianas, a partir dos últimos estudos elaborados pelo filósofo, sobre a ética e a estética da existência, ensaiando algumas possibilidades de aproximação entre as questões da formação docente e o conceito de cuidado de si. São tentativas de aproximação e distanciamento, de usar as ideias de Foucault para dizer de questões que ele mesmo não considerou em sua obra, mas que são potentes para ensaiar relações e afetações nas questões que nos interessam em nossos processos de pesquisa.

$\mathrm{O}$ artigo se organiza em quatro seções, considerando esta introdução como a primeira delas. Na segunda seção, apresento alguns dos referenciais foucaultianos que produziram as inquietações iniciais para pensar processos de formação. Na terceira seção, busco argumentar, efetivamente, sobre as possibilidades de análise construídas na pesquisa de doutorado, entremeando narrativas das estudantes de Pedagogia em seus diários de bordo com os referenciais foucaultianos sobre ética, cuidado de si e construção de sujeitos 
e subjetividades. Por fim, conclui-se o artigo, argumentando pela produtividade e pela inquietude de trabalhar com Foucault, tanto na pesquisa, quanto na formação docente.

\section{Ocupar-se consigo, inquietar-se: aproximações ao referencial foucaultiano}

Como tratei na tese da qual deriva este artigo (CASTRO, 2014), em seus últimos estudos, Foucault retoma a Antiguidade greco-romana pensando no imperativo do cuidado de si como possibilidade de uma ética política para o presente. Muito embora não pretendesse buscar soluções ou modelos, transpondo a configuração da Antiguidade diretamente para a contemporaneidade, Foucault dedica-se a pensar no "cuidado de si mesmo" (epiméleia heautoû) como um imperativo para uma existência bela, justa e memorável. 'Ocupar-se consigo', 'preocupar-se consigo' era algo que se fazia, entre os antigos ${ }^{\mathrm{v}}$, a partir de técnicas de si que colocavam o sujeito em uma relação com a verdade distinta daquela preconizada a partir do "momento cartesiano"vi . Sujeito e verdade, na Antiguidade, vinculavam-se a partir de "escolhas de existência', ou seja, da constituição de uma ética e de uma estética da existência, pautada em certos preceitos e regras de vida. Nesse sentido, a verdade não era 'dada' ao sujeito por um ato de conhecimento, como vem sendo concebido desde a Modernidade, mas, sob a perspectiva do cuidado de si, seria preciso um trabalho do sujeito sobre si mesmo (áskesis), um movimento de conversão, a partir do qual ele se

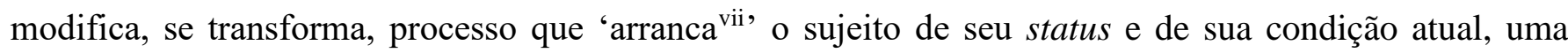
modificação ética. Assim, o cuidado de si seria o conjunto das transformações de si necessárias para que se possa ter acesso à verdade que guiará sua existência (FOUCAULT, 2011).

O sujeito do cuidado de si, como argumenta Gros (2011), é um sujeito de 'ação reta' mais do que um sujeito de conhecimentos verdadeiros. Apropriar-se do discurso verdadeiro não significa aprender a verdade sobre o mundo ou sobre si mesmo, mas assimilar, "no sentido quase fisiológico do termo, discursos verdadeiros que sejam auxiliares para afrontar os acontecimentos externos e as paixões interiores” (GROS, 2011, p. 476). A verdade, desse modo, seria 'etopoética', ou seja, "uma verdade que pode antes ser lida na trama dos atos realizados e das posturas corporais, do que decifrada no segredo das consciências ou elaborada no gabinete dos filósofos profissionais" (idem, p. 478).

Tratava-se, portanto, de uma ascese, um trabalho sobre si mesmo, o qual, diferentemente da acepção cristã, não se dava pela renúncia de si. Ao contrário, o cuidado de si era um voltar-se para si mesmo, um princípio de 'agitação', de 'movimento', de 'permanente inquietude' no curso da existência. Foucault (2011) delimita três momentos do cuidado de si na Antiguidade: o "momento socrático", estabelecido pelo filósofo a partir do diálogo "Alcebíades'; o "momento helenístico", considerado a idade de ouro da cultura do cuidado de si mesmo; e o "momento cristão", localizado na passagem do ascetismo pagão ao ascetismo 
cristão. No primeiro momento, o cuidado de si estava dirigido para o jovem que, abandonando a adolescência, deveria se preparar para o governo da pólis, ou seja, deveria cuidar de si para bem governar, participar da vida política. Além disso, como o princípio do cuidado de si era um privilégio de elite e de homens livres, implicava delegar a outros (escravos) o trabalho e o cuidado material. Nesse contexto, o ocupar-se consigo mesmo estava intimamente relacionado ao "conhecer a si mesmo" (gnôthi seautón), pois era preciso perceber sua própria ignorância e descobrir 'a ignorância da ignorância', a fim de que houvesse o autoconhecimento e o conhecimento da verdade. Os preceitos do cuidado de si no "momento socrático" foram, mais tarde, retomados pelo cristianismo, tendo como objetivo a renúncia de si mesmo (FOUCAULT, 2011).

Foucault vai concentrar-se mais especialmente no período helenístico, no qual a finalidade do cuidado consigo não é mais a pólis, mas o 'si mesmo'. O cuidado de si torna-se um imperativo da relação consigo mesmo que se impõe a todos/as. Torna-se, portanto, coextensivo à vida, à arte de viver (tekne tou biou), uma obrigação permanente que deve durar a vida toda e fazer-se presente em todos os momentos da vida. Nesse sentido, o cuidado de si realiza-se pela ocupação consigo em termos de trabalho (áskesis).

Foucault (2011) argumenta que o cuidado de si pode ser pensado, primeiramente, como uma 'atitude geral', como certo modo de encarar as coisas, de estar no mundo, de praticar ações e ter relações com outros - uma atitude para consigo, para com os outros e para com o mundo. Segundo, como certa 'forma de atenção' ao que se pensa e ao que se passa no pensamento. Além disso, como exercícios (práticas) de si para consigo, seria uma atividade vigilante, contínua, aplicada e regrada, visando à modificação.

Outro aspecto fundamental do cuidado de si da Antiguidade helênica é que ele conduz o sujeito a uma "ética da imanência", inscrevendo "uma ordem na própria vida, mas uma ordem imanente, que não seja sustentada por valores transcendentais ou condicionada do exterior por normas sociais" (GROS, 2011, p. 479). A estética de existência, nesse sentido, constitui uma existência ética que não é direcionada por um código moral, por leis ou prescrições religiosas transcendentais. A elaboração ética de si não era uma obrigação para todos, mas sim uma escolha pessoal de existência, compondo "práticas racionais e voluntárias" pelas quais os sujeitos não apenas determinam regras de conduta para si mesmos, "como também buscam transformar-se, modificar-se em seu ser singular e fazer de sua vida uma obra que seja portadora de certos valores estéticos e que corresponda a certos critérios de estilo" (FOUCAULT, 2006a, p. 193).

Foucault (2006a) distingue três tipos de moral. O 'código moral', que é formado por um conjunto de valores e regras de conduta propostas aos sujeitos a partir de certos aparelhos prescritivos, como a família, as igrejas e as instituições educativas. A 'moralidade dos comportamentos', ou seja, os comportamentos 'reais' dos sujeitos em relação ao código proposto, por exemplo, se há maior ou menor submissão a um princípio de conduta, se há obediência ou resistência a uma interdição, respeito ou 
negligência a certos valores. E um terceiro tipo seria a 'constituição de si como sujeito moral', ou seja, as diferentes maneiras de o sujeito "se conduzir moralmente" a partir dos elementos prescritivos que constituem o código, constituindo-se como "sujeito moral” de suas ações. É nesse último tipo que Foucault situará a ética da existência na Antiguidade, ou seja, não se trata de uma moral de sujeição, de submissão aos códigos prescritos, mas de uma liberdade que implica escolhas, decisões éticas a partir de códigos disponibilizados nessa cultura. A incitação ao cuidado de si, portanto, estende-se como possibilidade de condução da existência a todos/as, embora não se configure como 'lei universal': trata-se sempre de uma escolha de modo de vida que possibilita uma separação entre aqueles que escolheram esse modo de vida e os outros (FOUCAULT, 2011).

Outra questão importante na problematização do cuidado de si na Antiguidade greco-romana é que não se tratava de um retorno a si mesmo 'egoísta' ou 'individualista'. Não se tratava de uma "autocontemplação satisfeita e prazerosa", de uma "busca narcísica, fascinada e deslumbrada de uma verdade perdida do eu" (GROS, 2011, p. 482). Nesse sentido, o outro era indispensável. Constituir um êthos, isto é, um modo de ser e de se conduzir, apesar de pessoal, não é uma escolha solitária, implica relações complexas com outros, considerando que o cuidado de si é ético em si mesmo (FOUCAULT, 2006a). Cuidar de si implica o sujeito em um dilema ético: como se pode praticar a liberdade? O que Foucault (2006a) sugere é que ela fosse praticada eticamente a partir do trabalho sobre si mesmo, para que a prática de liberdade tomasse forma em um êthos que fosse bom, belo, honroso, respeitável e memorável. Cuidar de si, portanto, implica estabelecer relações éticas com os 'outros' na pólis, na comunidade, nas relações interindividuais: "[...] aquele que cuidasse adequadamente de si mesmo era, por isso mesmo, capaz de se conduzir adequadamente em relação aos outros e para os outros" (FOUCAULT, 2006a, p. 265). Além disso, o 'outro' no cuidado de si assume a forma do mestre, do guia, do conselheiro ou do amigo. A ação do 'outro', nesse caso, pode ser a de direção, de condução, uma relação afetiva que, por sua vez, faz a mediação na relação do indivíduo com sua constituição de sujeito (FOUCAULT, 2011).

\section{Ética e cuidado de si: ensaiando aproximações com Foucault para problematizar a formação docente}

Apresentados os elementos que dizem das teorizações foucaultianas sobre o cuidado de si e as técnicas para produzir uma verdade na condução de si mesmo, nesta seção, passo a algumas possíveis articulações e tentativas de aproximação desse referencial com a questão dos processos de formação docente, retomando elementos que foram constitutivos de uma pesquisa de doutorado, conforme anunciado na introdução deste artigo (CASTRO, 2014). Antes, faço a ressalva de que Foucault não pretendia tomar o 'cuidado de si' como solução para o tempo presente, diretamente aplicável ao que somos hoje. Com 
Foucault, podemos buscar, nas configurações éticas da Antiguidade, algumas indicações para a ética do presente. Suas teorizações são potentes para pensar e criar modos de subjetivação contemporâneos, modos de tecer esteticamente a própria existência.

Em primeiro lugar, trago as possibilidades da formação como atividade ligada ao cuidado de si e à elaboração ética e estética da vida e da docência. A formação colocando em funcionamento certas práticas de si que provocariam constantes abalos e deslocamentos nos modos de se tornar docente. Práticas ascéticas para pensar e ser diferentemente. Formação ético-estético-política: constituir modos de se conduzir na docência e na vida, tecendo subjetividades menos normatizadas, recusando o jogo do poder como dominação e estratégia de subjugação do outro. O projeto formativo ${ }^{\text {vii }}$ da disciplina Gênero, Sexualidade e Educação (GSE) seria uma composição de técnicas de si, pelas quais as estudantes passam a se ocupar consigo mesmas e a exercitar modificações éticas que as 'arrancam' de seu status de invisibilidade dos modos pelos quais as relações de gênero e as sexualidades são construídas e posicionadas em jogos de poder que hierarquizam e subordinam. Técnicas que incluem o ver-se, o narrar-se e o pensar-se enredadas por esses jogos, como a 'escrita de si' nos diários de bordo; a participação nas discussões promovidas durante as aulas, o contato com ideias antes impensadas sobre os gêneros e as sexualidades, com diferentes (e por vezes divergentes) modos de pensar, sentir e agir diante dessas ideias; a participação nas discussões provocadas pelas imagens, vídeos, filmes como artefatos direcionados à problematização de si e do mundo.

As proposições lançadas nas aulas partem da ideia de que é preciso constituir um êthos, um modo de ser e de se conduzir a partir da experiência com a disciplina GSE. Ao discutir, por exemplo, o machismo e as violências de gênero, são notórios os incômodos das estudantes em perceber que estão enredadas por essas relações, que elas mesmas são produto e, por vezes, produtoras de enunciados e práticas machistas. Incomoda perceber que as construções em torno do 'amor romântico' contribuem para manter posições de sujeito e privilégios de gênero, como a submissão e a vitimização femininas e a manutenção de 'liberdades' masculinas. No caso da homofobia, outro exemplo importante, os incômodos são ainda maiores, pois as estudantes passam a se colocar no lugar de quem pratica discriminações nas piadas, nos comentários cotidianos, nas conversas com amigas/os e familiares, lugar em que elas não se viam antes de participar da disciplina. Tal incômodo tira sua tranquilidade, pois, até então, acreditavam que ser homofóbica envolveria apenas situações de violência física e xingamentos contra pessoas homossexuais.

O modo como a disciplina GSE funciona, sugere às estudantes essa 'atitude geral' de vigilância de si, como propõe Foucault (2011), não apenas no sentido de terem atitudes consideradas 'politicamente corretas', mas apontando direcionamentos para outros modos de lidar com as questões centrais da disciplina, em especial quando se trata das formas normatizadas de relação consigo e com os outros. A disciplina conclama ao cuidado de si como um modo de estar no mundo, praticando ações, relacionandose com outros, mas também como 'forma de atenção' ao que se pensa e ao que se passa no pensamento. 
Como viver nessa intranquilidade? Como constituir um modo de viver com questões antes impensadas? As estudantes narraram em seus diários de bordo alguns dos conflitos vivenciados no processo de se envolver com a disciplina GSE, narrativas que apresentam o movimento para constituir modos de lidar com a problematização de si:

"Estou começando a perceber que estou cada vez mais me tornando uma 'chata' $e$ as outras pessoas estão percebendo isso. As pessoas estão pensando duas vezes antes de falar qualquer coisa comigo, pois estou praticando uma mudança de olhar sobre as coisas e o que antes eu não via agora não deixo escapar! Eu realmente mudei a minha lente!" (Catarina $-1 \%$ 2013) ${ }^{\text {ix }}$.

“Eu preciso exercitar mais a chatice, me pego às vezes 'tímida' para discutir alguns temas, com algumas pessoas, como os meus pais, por exemplo. Mas tenho tentado" (Alcione $-1 \%$ 2013).

'Ser chato' significa causar aborrecimentos, irritações, constrangimentos. Importunar, incomodar. Se, na convivência social, o sujeito adjetivado como 'chato' pode se tornar indesejável e dispensável, talvez seja oportuno pensar nos significados de assumir esse lugar a partir das aulas da disciplina GSE. Por que adjetivamos como 'chato' quem assume uma postura questionadora? Problematizar e colocar-se contra os processos normatizadores é 'ser chato'? Autoadjetivar-se como 'chato', desejar 'exercitar mais a chatice' são elementos que compõem um sujeito-forma, como argumenta Foucault (2006a), que é maleável e se modifica diante das contingências das relações sociais. Um sujeito multifacetado, sem forma definitiva. Sujeitos-docentes em formação, que podem assumir muitas formas, a partir da relação consigo. O 'ser chato', nesse caso, deixa de ter seu significado comum de atribuição social desqualificante, tornando-se uma estratégia de ação e uma atitude de incorporação ao cotidiano de outros modos de pensar, agir e sentir.

"Mudar as lentes", "mudar o olhar sobre as coisas", "não deixar mais escapar coisas que não se via" são atitudes que inserem as estudantes em jogos de poder e verdade, de constituição de si como sujeitos-docentes, como sujeitos de gênero e de sexualidade, jogos que envolvem conhecer o que antes era ignorado, perceber o que era antes imperceptível. As estudantes colocam-se nesse jogo com os outros, assumindo lugares que parecem não ser requisitados por pessoas do seu convívio, como familiares e amigos/as. 'Ser chato' porque questiona padrões e privilégios de gênero, porque problematiza hierarquias das sexualidades, porque abandona ou ressignifica alguns valores. O 'ser chato', nesse caso, figura como efeito das discussões que a disciplina GSE promove e, mesmo com alcances variáveis, parece modificar as relações de algumas estudantes consigo mesmas, 'arrancando-as' de seu status habitual.

"Foi muito difícil fazer as reflexões e principalmente perceber as situações ao meu redor. Eu tinha uma concepção muito bem construída e foi muito difícil confrontar tudo. Essa foi uma disciplina muito difícil, em vários momentos me senti 
contrariada, em outros, confusa, assustada, foram vários os sentimentos" (Denise $-2 \% / 2012$ ).

“[...] comecei a ter no papel anotado situações que me intrigavam e assim percebi não mais apenas em meus pensamentos, mas ali, concretizado no papel, que vivo rodeada de ações que não gostaria de presenciar, aliás, percebi ali que vivemos todos numa sociedade preconceituosa e impositora de costumes, ideias, ações e até pensamentos" (Tayla - 2\%/2012).

O cuidado de si como atividade ética impõe ao sujeito, a partir do trabalho sobre si mesmo, uma transformação advinda da insatisfação com um certo modo pelo qual se conduz a existência. Abre-se, então, a possibilidade de elaborar outros êthos, de fazer outras escolhas éticas, de criar esteticamente a própria existência a partir da inconformidade. Isso não se faz facilmente. A estudante Catarina havia apontado uma “mudança de lentes", passando a olhar diferentemente para o mundo. Denise e Tayla parecem também ter entrado nesse jogo: com 'novas lentes' vêm outros modos de perceber o mundo e, consequentemente, as dificuldades em confrontar a si mesmas, as suas concepções tão bem construídas. Um emaranhado de sentimentos se constitui como estratégia de combate à paralisia do pensamento: sentir-se contrariada, confusa, assustada. Perceber-se "rodeada de ações que não gostaria de presenciar". Cuidar de si implica, nesse caso, um estado de constante agitação, de movimento, de inquietude, algo que impõe ao sujeito relações conflitantes consigo mesmo, que exigem negociações.

"Esse (gênero e sexualidade) é um tema que muito me afeta, pois mexe comigo, com meus valores, minhas crenças, minhas "paranoias", minha estranheza... com tudo! Nossas discussões confrontam meu eu, me fazem pensar no que eu acredito para a minha vida!" (Pâmela - 1\%2012).

Escolhas, decisões. Elementos que compõem uma ética de existência. O cuidado de si como decisão ética envolve um trabalho sobre si com vistas à transformação de si. Caberia perguntar: que transformação? É preciso, nesse caso, desprender-se dos juízos de valor, ou seja, "transformações positivas" ou “negativas”, mas pensar em termos da pergunta que orienta muitas das problematizações foucaultianas: o que estamos ajudando a fazer de nós mesmos? O que estamos nos tornando? Fazer esse movimento não significa, necessariamente, declinar de valores e crenças construídas. Essas também são escolhas. Em seu registro narrativo, Pâmela demonstrou isso: embora tenha "mexido" com valores, crenças e "paranoias", embora tenha confrontado seu 'eu' (aparentemente fixo e coerente), a estudante reafirmou o que "acredita para a sua vida". O fato de a disciplina GSE se organizar com a proposta de experienciar modos mais plurais de lidar com os sujeitos, as relações, os valores, não significa que todas as estudantes adotarão essa proposta. Passar pela disciplina pode, inclusive, significar que nada lhe passa, nada lhe acontece (LARROSA, 2014). Isso implica pensar que a disciplina propõe alguns modos de as estudantes se conduzirem, sugere alguns 
elementos para construir um êthos, propõe alguns valores. No entanto, nem sempre eles serão incorporados, pois são justamente isso, propostas, sugestões e não leis ou códigos morais normativos.

"Confesso que essa é uma discussão ainda bastante nova para mim. Sempre morei em uma cidade bem pequena e as diferenças sempre foram algo que não se evidenciava muito no âmbito social. [...] Por esse motivo, não se questionava muito alguns acontecimentos no sentido de procurar entender, mas eram logo encarados pela não aceitação e por mecanismos de coerção" (Luana - 1\%2012).

A existência de Luana foi marcada por histórias de 'invisibilidade', "não aceitação" e "mecanismos de coerção" no que diz respeito às diferenças. A vida na "cidade bem pequena" talvez tenha sido constituída a partir de valores e regras de conduta propalados por 'aparelhos prescritivos', como a família, a escola e as igrejas. Códigos morais que, como salienta Foucault (2006a), implicam uma moralidade dos comportamentos, ou seja, se os sujeitos se submetem mais ou menos completamente a um princípio de conduta, se obedecem ou resistem às interdições ou prescrições. Estar (ou diria mesmo permanecer) em uma disciplina que se propõe a discutir relações de gênero e sexualidades, sob uma perspectiva de problematização dos processos de construção das diferenças, pode ser considerado uma escolha ética no sentido de buscar, a partir da formação docente como áskesis, uma modificação de si. Para a maioria das estudantes, como narra Luana, as discussões em torno das relações de gênero e sexualidades é algo 'novo', fato que as coloca na condição de sujeito moral, devendo conduzir-se a partir dos elementos prescritivos que constituem os códigos morais, mas também a partir das propostas de conduta da disciplina. Esse processo implica considerar que existem margens de variação ou transgressão em relação a esses códigos e a essas propostas. Não se trata, portanto, de um jogo binário entre os valores trazidos pelas estudantes e aqueles visibilizados pela disciplina. Como princípio de agitação e movimento, o cuidado de si supõe que os sujeitos estejam sempre em negociação com as referências para a condução de si que existem em sua cultura.

Coloca-se, desse modo, uma importante tensão no projeto formativo da disciplina GSE: de que modos é possível conduzir-se para uma elaboração ética de si, considerando a convivência entre crenças e valores previamente constituídos e as proposições da disciplina que, frequentemente, tensionam esses elementos? Essa discussão é especialmente relevante no que se refere ao enquadramento pelo discurso religioso, mais precisamente pelos modos de sujeição colocados em funcionamento por certas vertentes religiosas que fazem com que os sujeitos se reconheçam ligados à obrigação de colocar em prática seus preceitos, tomando-os numa acepção de verdade transcendental inquestionável. Uma questão que se coloca na relação das estudantes com a disciplina:

"Tenho recebido várias críticas na igreja e na família sobre a disciplina que estou fazendo sobre gênero. E ainda duvidam que vou terminar a disciplina. Dizem que 
não tem nada a ver comigo, pois sou serena e delicada para este tipo de assunto. A minha mãe no início ficou meio com receio, mas com o tempo ela me apoiou, que bom! Como profissional e pessoal me fará muito bem!!! Minhas irmãs têm muitos amigos gays e nem me criticam, mas na faculdade tem amigas que não olham com bons olhos a disciplina [...]. Não me importo, vou terminar!!!!!” (Lígia - 1\%2013).

Com a narrativa de Lígia, a tensão se visibiliza e isso faz pensar nas subjetividades como possibilidades de relações não normativas consigo mesmo, resistindo ao enquadramento em formas de vida socialmente prescritas. Embora o êthos religioso seja uma escolha de existência para Lígia, ela permanece na disciplina. Outras estudantes de Pedagogia declinam da opção de cursá-la, "não olham com bons olhos". E há ainda aquelas que, mesmo pouco dispostas a se conduzirem de modos que rompam com seu êthos religioso, também permanecem, como foi o caso de estudantes que registravam, em seus diários de bordo, a sua constante insatisfação, não consigo mesmas, mas com as discussões das aulas que se chocavam diretamente com os seus valores e suas crenças religiosas. Elas procuravam demonstrar como a disciplina apenas reforçava nelas as convicções religiosas, por exemplo, ao escrever sobre o "horror"x de presenciar imagens de carícias e beijos entre dois homens.

A estética da existência na contemporaneidade pode ser pensada, assim como na Antiguidade grecoromana, como algo que não é obrigação para todos, especialmente porque a constituição de uma existência ética, como foi explicitado anteriormente, não é direcionada por um código moral, por leis ou prescrições religiosas transcendentais. Não se trata, desse modo, apenas da moralidade dos comportamentos, se um sujeito obedece com maior ou menor intensidade ao código, se resiste a ele ou o incorpora em suas relações. A elaboração ética de si comporta escolhas pessoais de existência que visam fazer da vida "uma obra que seja portadora de certos valores estéticos e que corresponda a certos critérios de estilo" (FOUCAULT, 2006a, p. 193). No contexto da contemporaneidade, as práticas de si podem contrapor-se àquelas da Antiguidade, configurando-se como práticas de assujeitamento e disciplinamento (ORTEGA, 2002). Portanto, algumas estudantes podem estar se constituindo a partir de éticas orientadas para uma moralidade que mais assujeita do que liberta, como é o caso de algumas vertentes religiosas, especialmente aquelas por meio das quais os sujeitos se envolvem em práticas ascéticas pautadas no fundamentalismo da palavra bíblica. Sugere-se, assim, que a estética da existência seja pensada a partir de outros modos de se conduzir, entendendo que o 'ocupar-se consigo' está aliado ao 'inquietar-se', o que exige criatividade, abertura para o novo, tentativas, acertos e erros, como propõe Miskolci (2008). As práticas de si implicariam aprender e transformar-se para constituir "formas de resistência ao enquadramento em formas de vida socialmente prescritas. O cuidado de si repousa em uma ética da inconformidade, da rebeldia, da rejeição à normalização" (MISKOLCI, 2008, p. 235).

Ortega (1999) comenta sobre o modo de Foucault pensar a política a partir de suas experiências no Irã. Lá ele teria encontrado uma experiência política e de revolta que consiste na produção de uma relação 
consigo mesmo, entendida como conversão ao poder. Foucault passa a tomar política como ética, como modo de se rebelar "contra formas estabelecidas de subjetividade e aspirando à criação de outras novas" (ORTEGA, 1999, p. 34). Constrói, assim, a noção de que não há transformação do mundo sem a transformação de si. Essa concepção foucaultiana de política pode ser fecunda para pensar a formação docente, no sentido de produção de outras subjetividades, a partir do reconhecimento de que somos sujeitos de gênero e sexualidade, de que as relações de gênero e as sexualidades são organizadoras da vida em sociedade, são construções culturais e históricas. Dar-se conta desses argumentos poderia constituir um êthos de intolerância aos preconceitos, discriminações, violências, em modos de se conduzir numa constante inquietação com o mundo, com as relações sociais. Cuidar de si para, ao se transformar, transformar o mundo, o que não se faz sem o cuidado com o outro. Implica, portanto, menos uma relação 'individualista' e 'egoísta' consigo mesmo, mas “uma modulação intensificada da relação social. Não se trata de renunciar ao mundo e aos outros, mas de modular de outro modo esta relação com os outros pelo cuidado de si" (GROS, 2008, p. 132).

$\mathrm{Na}$ Antiguidade greco-romana, o 'outro' estava presente no cuidado de si por meio de atividades eminentemente sociais, como conversações, trocas de cartas, ensinamentos em escolas. Além disso, o 'outro' também poderia figurar como mestre, conselheiro, amigo. Nesse sentido, é que o projeto de formação da disciplina GSE não se restringe ao espaço-tempo das aulas, escapando às paredes da sala de aula e ao que acontece ali para reverberar no cotidiano das estudantes, onde elas podem inquietar outros familiares, amigas/os, colegas de trabalho, docentes e crianças das escolas em que realizam seus estágios com as problematizações nas quais se envolvem com as aulas. Assim, "não se cuida de si para escapar do mundo, mas para agir como se deve" (GROS, 2008, p. 132). Nas narrativas das estudantes, o 'outro' pode aparecer como regulador ou limitador das possibilidades de incorporação das discussões da disciplina no cotidiano (CASTRO, 2014). Por exemplo, quando Alcione escreve sobre suas dificuldades em discutir alguns temas com seus pais; quando Luana escreve sobre a educação recebida por ela em uma cidade 'pequena', em que as diferenças ficavam relegadas a não aceitação e coerção e como isso traz dificuldades com a disciplina; quando Lígia relata as críticas que vinha recebendo na igreja, na família e na própria faculdade por estar cursando a disciplina. Outras situações também são narradas pelas estudantes, quando elas passam a perceber que discutir questões de gênero e sexualidade ou mesmo incorporar em suas vidas uma certa perspectiva de problematização dessas questões frequentemente resulta em conflitos com seus namorados, amigas, familiares, colegas de trabalho e de faculdade. Porém, as estudantes também narram episódios em que perceberam mudanças nas relações com os outros a partir da disciplina, como relata Catarina: "As pessoas estão pensando duas vezes antes de falar qualquer coisa comigo".

O cuidado de si e o cuidado com o outro na educação exigiria, como propõe Gallo (2006), a reciprocidade, uma espécie de 'reflexo' em que o cuidado com o outro pode redundar no cuidado de si, 
inscrito em contextos de práticas de liberdade e não de governo do outro, ou seja, de controle e domínio das vontades. O 'inquietar-se' produzido na formação docente estaria política e eticamente comprometido com essas práticas, em que as/os docentes trabalham sobre si para educar o outro. Um jogo de reciprocidade de uma ação ética, "em que uns se fazem livres aprendendo da liberdade dos outros; em que uns se fazem livres na medida em que ensinam a liberdade aos outros" (GALLO, 2006, p. 188). Retoma-se, assim, a proposta de política como ética que recusa formas normatizadas (e normatizadoras) de subjetividades (ORTEGA, 1999), por conseguinte, pensando a docência como experiência transformadora de si que possibilita, nas práticas pedagógicas, transformar o outro como condição para a mudança social.

O ‘outro’ na disciplina GSE também se materializa na figura do docente, o que faz pensar na posição que este ocupa no projeto formativo. Foucault (2011) distingue na Antiguidade a figura do mestre e do professor. A partir de seus estudos, argumenta que o professor seria um educador no sentido 'tradicional' do termo, alguém que ensinava verdades, dados e princípios. Contudo, o mestre seria o operador na reforma do indivíduo, o mediador da relação do indivíduo com sua constituição de sujeito. É delicado e arriscado pensar nesse posicionamento simultâneo de pesquisador e docente, mas deseja-se pensá-lo como esse lugar do mestre, de quem opera ações sobre os outros, estendendo-lhes a mão para que saiam do 'estado' (modo de vida) no qual estão, como propõe Foucault (2011). No livro “A hermenêutica do sujeito", Foucault apresenta Sócrates como aquele que tinha por ofício incitar os outros a se ocuparem consigo mesmos, a terem cuidados consigo. $\mathrm{O}$ 'incitar', nesse sentido, adquire múltiplos sentidos: interrogar, examinar, exortar, ministrar ensinamentos, interpelar as pessoas e despertar algo nelas. Esse pode ser o lugar que o docente ocupa no projeto formativo da disciplina GSE, certamente não se trata de um lugar tranquilo e cômodo, mas, como propõe Gallo (2006), esse seria um lugar de reciprocidade, em que o docente, ao trabalhar sobre si mesmo, ocupa-se consigo para que as estudantes se ocupem consigo mesmas. Ser docente na disciplina GSE é a oportunidade de assumir desassossegos e de buscar se desacomodar da docência como posição de sujeito 'segura' e 'dominante', como sujeito-forma, assumindo uma 'atitude experimental' na relação consigo e com os outros. Trata-se de uma ética que exige um princípio de permanente inquietude, coextensivo à vida, à arte de viver (tekne tou biou) (CASTRO, 2014).

Desse modo, não se trata apenas de 'transferir' a produção científica no campo das relações de gênero e sexualidades para as estudantes, mas utilizá-la como ferramenta de inquietação, problematização. Não se trata da substituição 'direta', pelas estudantes, de seus saberes por aqueles construídos cientificamente. Trata-se de como as estudantes estabelecerão relações com essa produção acadêmica, o que elas farão com isso, de que modos essa produção lhes instiga a pensar a si mesmas e de que modos uma disciplina poderia se constituir como espaço-tempo ético-estético-político de resistência aos poderes subjetivantes (LOPONTE, 2005). Algo que está aberto às contingências dessas relações, ou seja, a partir dos embates, de como a produção científica pode desestabilizar certezas e convicções e como isso reverbera 
no cotidiano. Articula-se, desse modo, a ideia de uma formação como cuidado de si, que introduz entre o sujeito e o mundo certa distância, que é constitutiva de suas ações no mundo.

É essa distância que me permite não me deixar fascinar pelo objetivo imediato; impede a precipitação; permite um retorno a si, a partir do qual posso consultar o catálogo dos meus deveres e agir de maneira circunstanciada, ao invés de agir com urgência (GROS, 2008, p.132).

Uma formação ético-estético-política estaria pautada na relação das estudantes consigo mesmas e com sua futura atividade docente como invenção de si e com a criação de novos modos de subjetivação para a docência. Uma formação que não teria como objetivo um sujeito plenamente 'formado', ‘desenvolvido', mas um ‘quase-sujeito', sempre em constituição, em contínua transformação. Uma decisão ético-estética que exige trabalho contínuo, mas que não se relaciona com uma coação ou prescrição, não é uma obrigação para todas/os. Pensando na Antiguidade greco-romana e nas possibilidades de articulação com a ética e a estética da existência, não se trata de exaltar as subjetividades antigas, glorificá-las e aplicálas aos nossos modos de ser contemporâneos, passando a compor mais um dos modelos de docência (LOPONTE, 2005). Essa perspectiva de formação articula-se a partir do argumento de que as relações de gênero e as sexualidades estão em constante transformação, considerando as produções nas diversas áreas de conhecimento (Educação, Filosofia, Sociologia, Antropologia, História, etc.). São campos culturais e históricos que se modificam com as experiências dos sujeitos, com as disputas na produção de significados e na articulação com diversas outras temáticas (etnia, geração, religiosidade, nacionalidade, entre outras). Além disso, considera-se que 'relações de gênero' e 'sexualidades' remetem às multiplicidades de sujeitos, de práticas, de desejos e prazeres, de formas de ser, agir, sentir, pensar. Uma formação docente poderia dar conta dessa movimentação? Importa o que essa formação pode fazer pensar ou o que podemos pensar sobre nós mesmos e sobre a formação a partir dela ou contra ela. Importa também essa formação em relação às escolas: que poética e ética são possíveis hoje nessas escolas? Que espaços para práticas de liberdade são possíveis? Que “etopoéticas docentes”, como propõe Loponte (2005), são possíveis nessas escolas? Questões que permanecem sem uma resposta conclusiva, mas que são inquietantes para pensar os projetos das diferentes instâncias de formação.

\section{Finalizando: continuidade das inquietações junto a Foucault}

De que valeria a obstinação do saber se ele assegurasse apenas a aquisição dos conhecimentos e não, de certa maneira, e tanto quanto possível, o descaminho daquele que conhece? Existem momentos na vida onde a questão de saber se se pode pensar diferentemente do que se pensa, e perceber diferentemente do que se vê, é indispensável para continuar a olhar ou a refletir (FOUCAULT, 2001, p. 13). 
No trecho acima, ao falar de como pensa seu próprio trabalho, Foucault faz o anúncio de um descaminho, daquilo que o movimenta: a obstinação de saber para pensar e perceber diferentemente. Em outro momento, ao falar de seus livros, o filósofo diz que eles representam parte de sua história, das coisas vividas e experimentadas por ele, por exemplo, no período em que trabalhou em um hospital psiquiátrico, onde, depois de meses, começou a se perguntar: "Mas para que essas coisas são necessárias?" (FOUCAULT, 2006a, p. 29). Também menciona sua atuação nas prisões e em suas viagens: “Quando estava na Tunísia, vi pessoas serem presas por motivos políticos, e isso me influenciou” (idem, p. 297). Das coisas vividas e experimentadas, também estão suas leituras, como a de Nietzsche: “Tive a impressão de descobrir um autor muito diferente daquele que me havia sido ensinado. Eu o li apaixonadamente e rompi com minha vida" (ibidem, p. 297-298). A trajetória e a perspectiva de Foucault sobre sua vida e seu trabalho inspiram a pensar e elaborar os processos da pesquisa e a construção do pesquisador como alguém que pensa e percebe o mundo diferentemente. Tal operação foi estendida às estudantes que compuseram esses processos junto ao pesquisador: o convite a pensar, sentir, agir diferentemente em relação àquilo que lhes era 'comum', 'natural', 'normal', 'inquestionável', como pessoas e como futuras docentes. Se Foucault foi tocado pelos fatos, pelos acontecimentos, enfim, pelas experiências vividas, isso nos faz pensar no processo de pesquisa e no projeto formativo da disciplina GSE como afastados de qualquer pretensa neutralidade. Ao contrário, em tempos de tantas perseguições às liberdades de expressão, de ensinar e de aprender, é preciso que sejam políticos, no sentido de que conduzam a enfrentar os perigos e a violência do pensar diferentemente, do agir diferentemente, de urdir outras tramas nos jogos de poder/saber/verdade.

Alfredo Veiga-Neto (2005) argumenta que o trabalho histórico-filosófico de Michel Foucault pergunta por uma ontologia do presente, ou seja, "uma ontologia crítica de nós mesmos", formulada a partir da questão: “que se passa com nós mesmos?”. Essa questão “põe em relevo o sentido e o valor das coisas que acontecem conosco no presente, não mais perguntando sobre as condições necessárias para determinar a verdade das coisas" (VEIGA-NETO, 2005, p. 46). A questão principal que movimentou a pesquisa que dá origem a este artigo parte de uma discussão que pode ser considerada atual: o atravessamento dos processos de constituição de sujeitos na formação docente, nas sexualidades e gêneros. Não no intuito de perguntar por uma verdade sobre essas questões, qual seria o/a docente ideal, a escola ideal, o currículo de formação docente mais adequado ou mais correto, mas para fomentar questionamentos sobre as teias que nos capturam e nos fazem pensar e agir de determinadas maneiras sendo docentes, estudantes, enfim, sujeitos.

Ao nos envolvermos com o pensamento de Foucault, torna-se um imperativo que passemos a uma crítica do que somos, do que nos tornamos, das implicações políticas e culturais de tomarmos certos conhecimentos como acepções de verdade, buscando, como sugere o filósofo, conhecimentos que nos levem aos descaminhos. Isso instiga a pensar nas potencialidades da disciplina GSE, que discute questões 
pouco debatidos em outras disciplinas, em outros momentos formativos no curso de Pedagogia (CASTRO, 2014). Como destaca Veiga-Neto (2005, p. 46), Foucault se interessa em perguntar como "chegamos a ser o que somos, para, a partir daí, podermos contestar aquilo que somos”. Considera-se tal questão relevante para pensar a formação docente na contemporaneidade: como nos tornamos os/as docentes que somos? Como contestar isso que imaginamos ser? O pensamento para Foucault (2006a, p.231-2) é o que nos permite "tomar distância" em relação aos nossos modos de fazer e de reagir, interrogando-os "sobre seus sentidos, suas condições e seus fins". Como ele mesmo nos diz, "o pensamento é liberdade em relação àquilo que se faz, o movimento pelo qual dele nos separamos, constituímo-lo como objeto e pensamo-lo como problema".

Pensar a constituição de sujeitos no currículo universitário de formação docente remete a inúmeras inquietações, para as quais não temos respostas 'prontas', mas servem para inquietar outros pensamentos, outras pesquisas, outros processos formativos: que discursos e enunciados sobre sexualidades e relações de gênero circulam por esse currículo e de que modos formam sujeitos-docentes? Que discursos podem ser acionados na perspectiva de uma formação que contemple as multiplicidades de sexualidades e gêneros? De que modos os enunciados que circulam e que são produzidos no contexto de uma disciplina que discute as relações entre sexualidades, gêneros e educação, do currículo do curso de Pedagogia, podem produzir sujeitos-docentes em uma perspectiva 'plural'? Aproximando-nos das proposições de Foucault, intentamos problematizar as relações entre saber/poder/verdade que capturam e formam sujeitos no âmbito de discussões acerca das relações de gênero, sexualidades e educação. Mais especificamente, pensar os modos pelos quais as estudantes do curso de Pedagogia se envolvem em processos de subjetivação que instituem pensamentos, ações, sentimentos, enfim, modos de serem docentes (CASTRO, 2014).

A noção foucaultiana de 'sujeito ético', que se constitui em práticas de si, de 'ação moral sobre si mesmo', foi uma ferramenta inquietante para as problematizações da pesquisa. Uma disciplina que discute e problematiza relações de gênero e sexualidades pode funcionar como um campo de constituição de sujeitos que instauram relações consigo mesmos, ao participarem de debates, ao lerem textos, ao pensarem e narrarem sobre como seus corpos se produzem como superfícies de inscrição das marcas dos gêneros e sexualidades. Assim, instauram-se relações das estudantes consigo mesmas por meio das práticas da disciplina GSE, produzindo múltiplas subjetividades, definidas como os modos pelos quais os sujeitos (as estudantes, o docente) se observam, se reconhecem em um lugar de saber e de produção de verdades a partir das "práticas, as técnicas, os exercícios, num determinado campo institucional e numa determinada formação social” (FISCHER, 2012, p. 54).

Assumir as práticas colocadas em ação por uma disciplina acadêmica como tecnologias de subjetivação é um modo de pensá-las como atividade em que as estudantes tomam distância em relação às suas maneiras de pensar, de agir, de sentir, ou seja, podem 'separar-se de si mesmas', problematizar valores, 
crenças, conhecimentos solidamente constituídos. Ao tomarmos de empréstimo alguns elementos da crítica foucaultiana, sempre pronta a se voltar contra si mesma, podemos nos sentir desafiados/as a encarar nosso trabalho de pesquisa e nossa atuação na formação docente em sua precariedade, vivendo-os como possibilidade de transformação, "desejo de distanciar-se de nós mesmos", de pensar diferente do que pensamos. Nesse processo, aprendemos a transformar constatações em 'problemas', como uma atitude ética e política de enfrentar os perigos do nosso tempo, mais que apontar soluções, enfim, aprendemos o exercício da dúvida permanente (FISCHER, 2012; VEIGA-NETO, 2005).

\section{Referências}

CASTRO, Roney Polato de. Experiência e constituição de sujeitosdocentes: relações de gênero, sexualidades e formação em Pedagogia. (Tese - Doutorado em Educação). 2014.

DELEUZE, Gilles. Conversações. Trad. Peter Pál Pelbart. São Paulo: Editora 34, 1992.

FISCHER, Rosa. M. Bueno. Trabalhar com Foucault: arqueologia de uma paixão. Belo Horizonte: Autêntica, 2012.

FOUCAULT, Michel. História da sexualidade II: O uso dos prazeres. 9 ed. Trad. $\mathrm{M}^{\mathrm{a}}$ Thereza da Costa Albuquerque. Rio de Janeiro: Edições Graal, 2001.

FOUCAULT, Michel. Ética, Sexualidade, Política. Ditos \& Escritos V. 2 ed. Org. Manoel Barros da Mota. Trad. Elisa Monteiro e Inês Autran Dourado Barbosa. Rio de Janeiro: Forense Universitária, $2006 a$.

FOUCAULT, Michel. Microfísica do Poder. 22 ed. Org. e Trad. Roberto Machado. Rio de Janeiro, Graal, $2006 b$.

FOUCAULT, Michel. Estratégia, Poder-Saber. Ditos \& Escritos IV. 2 ed. Org. Manoel Barros da Mota. Trad. Vera Lúcia A. Ribeiro. Rio de Janeiro: Forense Universitária, 2006c.

FOUCAULT, Michel. A hermenêutica do sujeito: curso dado no Collège de France (1981-1982). Trad.: Márcio Alves da Fonseca e Salma Tannus Muchail. 3 ed. São Paulo: Martins Fontes, 2011.

GALLO, Silvio. Cuidar de si e cuidar do outro: implicações éticas para a educação dos últimos escritos de Foucault. In: GONDRA, J.; KOHAN, W. (Orgs.). Foucault 80 anos. Belo Horizonte: Autêntica, 2006. p. 177-189.

GROS, Frèderic. O cuidado de si em Michel Foucault. In: RAGO, Margareth; VEIGA-NETO, Alfredo (Orgs.). Figuras de Foucault. Belo Horizonte: Autêntica, 2008. p. 127-138.

GROS, Frèderic. Situação do curso. In: FOUCAULT, Michel. A hermenêutica do sujeito: curso dado no Collège de France (1981-1982). Trad.: Márcio Alves da Fonseca e Salma Tannus Muchail. 3 ed. São Paulo: Martins Fontes, 2011. p. 455-493.

KASTRUP, Virgínia.; TEDESCO, Silvia.; PASSOS, Eduardo. Introdução. In: Políticas da cognição. Porto Alegre: Sulina, 2008. p. 9-17.

LARROSA, Jorge. Tecnologias do Eu e Educação. In: SILVA, T. T. da (Org.). O sujeito da educação: estudos foucaultianos. Petrópolis, RJ: Vozes, 2002. p. 35-86.

LARROSA, Jorge. Tremores: escritos sobre experiência. Trad.: Cristina Antunes e João Wanderley Geraldi. Belo Horizonte: Autêntica, 2014. 
LOPONTE, Luciana G. Docência artista: arte, estética de si e subjetividades femininas. Tese (Doutorado - Educação). Programa de Pós-Graduação em Educação, Universidade Federal do Rio Grande do Sul, Porto Alegre, 2005.

MISKOLCI, Richard. Estética da existência e pânico moral. In: RAGO, M.; VEIGA-NETO, A. (Orgs.). Figuras de Foucault. 2 ed. Belo Horizonte: Autêntica, 2008. p. 227-238.

ORTEGA, Francisco. Amizade e estética da existência em Foucault. Rio de Janeiro: Graal, 1999.

ORTEGA, Francisco. Da ascese à bio-ascese ou do corpo submetido à submissão do corpo. In: RAGO, Margreth; ORLANDI, Luis. B. L.; VEIGA-NETO, Alfredo. (Orgs.). Imagens de Foucault e Deleuze: ressonâncias nietzschianas. Rio de Janeiro: DP\&A, 2002. p. 139-173.

POL-DROIT, Roger. Michel Foucault: entrevistas. Trad.: Vera Portocarrero e Gilda Gomes Carneiro. São Paulo: Graal, 2006.

VEIGA-NETO, Alfredo. Foucault \& a educação. 2 ed. Belo Horizonte: Autêntica, 2005.

Recebido em: 22/04/2020.

Aceito em: 03/08/2020.

Notas:

${ }^{\text {i }}$ Professor da Faculdade de Educação e do Programa de Pós-graduação em Educação da Universidade Federal de Juiz de Fora. Membro do GESED - grupo de estudos e pesquisas em Gênero, Sexualidade, Educação e Diversidade (cadastrado no CNPq). E-mail: roneypolato@gmail.com Juiz de Fora. ORCID: https://orcid.org/0000-0002-6385-9096

ii Em uma entrevista, em 1975, Foucault afirma que era um pirotécnico, "fabrico alguma coisa que serve, finalmente, para um cerco, uma guerra, uma destruição" (in POL-DROIT, 2006, p. 69). Seu trabalho se daria em meio a uma 'guerra', pois seu discurso seria instrumental, como um saco de pólvora ou um coquetel Molotov.

iii $\mathrm{O}$ uso do feminino para se referir às estudantes é proposital, já que, ao longo dos semestres, há poucos estudantes que se autoidentificam como homens integrando a disciplina.

iv Por processos de dessubjetivação, estamos entendendo os modos de produção que instigam o sujeito a 'sair de si', 'olhar-se', 'dar um passo atrás', problematizar a si, o seu processo constitutivo, produzindo uma transformação, um 'outro de si mesmo'.

${ }^{v}$ Quando se tratar dos indivíduos na Antiguidade clássica, opto pela grafia no masculino, tendo em vista a cultura que segregava a participação na vida pública, privilegiando os homens.

vi Com essa denominação, Foucault remete-se não a um momento específico, mas ao movimento discursivo instaurado com as proposições de Descartes de que a verdade seria alcançada pelo sujeito em um ato de conhecer que não implica uma espiritualidade.

vii Sob inspiração foucaultiana, arrancar o sujeito de si mesmo diz da possibilidade de exercício do pensamento em que o sujeito se coloca sob exame, como objeto de problematização, produzindo outro de si mesmo.

viii Por projeto formativo entendem-se as disposições pedagógicas dos currículos e das disciplinas acadêmicas para organizar e realizar a formação docente, projeto este que se materializa a partir de significados específicos sobre formação, docência, escola etc. (CASTRO, 2014).

${ }^{\text {ix }}$ Os nomes das estudantes são fictícios, de modo a preservar seu anonimato na pesquisa. A referência à frente do nome diz do semestre e ano em que cada estudante participou da disciplina GSE.

"Na narrativa de uma das estudantes, a expressão "horror" foi utilizada para expressar o sentimento em relação a determinado filme exibido nas aulas - Milk, a voz da igualdade, que trazia em seu enredo trocas de carícias e beijos entre homens. 